\title{
利用红外相机调查青海三江源国家级自然保护区 中铁一军功分区兽类资源
}

\author{
李 佳 刘芳 张宇 李广良 李迪强* \\ (中国林业科学研究院森林生态环境与保护研究所/国家林业局森林生态环境重点实验室, 北京 100091)
}

\section{Using camera traps to survey mammals in Zhongtie-Jungong Area of Sanjiangyuan National Nature Reserve, Qinghai Province}

\author{
Jia Li, Fang Liu, Yu Zhang, Guangliang Li, Diqiang $\mathrm{Li}^{*}$ \\ Institute of Forestry Ecology, Environment and Protection, Chinese Academy of Forestry / Key Laboratory of Forest \\ Ecology and Environment of State Forestry Administration, Beijing 100091
}

三江源国家级自然保护区中铁一军功分区位 于青海省玛沁、同德、兴海3县交界处的黄河干流 峡谷地带 $\left(99^{\circ} 14^{\prime}-101^{\circ} 13^{\prime} \mathrm{E}, 34^{\circ} 18^{\prime}-35^{\circ} 29^{\prime} \mathrm{N}\right)$, 是一 个以保护和恢复区域自然生态环境, 维持和增强水 源涵养能力, 保护生物多样性为主要功能的自然保 护区，总面积77.1万ha。全区以山地地貌为主，海拔 $2,900-5,126 \mathrm{~m}$, 最高峰为阿尼玛卿雪山。该区属青 藏高原气候系统, 为典型的高原大陆性气候, 年均 气温 $3.7^{\circ} \mathrm{C}$, 年均降水量 $420 \mathrm{~mm}$ 。保护区内植被可分 为森林、灌从、山地草原和高寒沼泽 4 种类型。森 林主要分布于海拔3,180-3,600 $\mathrm{m}$ 的峡谷两岸, 以针 叶林和针阔混交林为主, 优势树种包括青海云杉 (Picea crassifolia)、祁连圆柏(Sabina przewalskii)、 白桦(Betula platyphylla) 等; 灌从主要分布于海拔 3,100-4,500 m的山地半阳坡、阴坡, 以山生柳(Salix oritrepha)、金露梅(Potentilla fruticos $a$ )等种类为优 势种; 山地草原主要分布于海拔3,100-3,400 $\mathrm{m}$ 的森 林下沿沟谷阳坡, 以早熟禾 (Poa annua) 为优势种; 高寒沼泽分布规律不明显, 整个保护区均有分布, 垭口、阴坡下部、沟谷滩地等处较常见，一般以嵩 草属(Kobresia) 植物为主。保护区内野生动物有雪豹 (Uncia uncia)、白唇鹿(Przewalskium albirostris)、林
榭(Moschus berezovskii)、马㭩(M. chrysogaster)、蓝 马鸡 (Crossoptilon auritum)、斑尾榛鸡 (Tetrastes sewerzowi)等(李迪强和李建文，2002; 国家林业局 西北林业调查规划设计院和中国水电顾问集团西 北勘测设计研究院, 2014 ${ }^{(1)}$ 。

自2003年三江源保护区晋升为国家级自然保 护区以来, 从未在中铁一军功分区开展过系统的动 物资源调查。为了解该区兽类资源状况，本研究于 2015年6-9月，使用红外相机进行了为期 70天的调 查，以摸清该保护区兽类资源及空间分布，并初步 分析放牧对野生动物活动的影响, 为保护区动物资 源的保护和长期监测提供基础数据。

\section{1 研究方法}

\section{1 红外相机设置}

2015年6-9月, 在中铁一军功分区选择中铁、军 功、洋玉和江群 4 个林场放置红外相机, 每个林场 9-15台, 共47台。相机放置于野生动物经常活动的 地点, 如兽径、水源点、取食痕迹较多处等, 固定 于离地面 80-120 $\mathrm{cm}$ 的树干上, 相机镜头与地面平 行或与之呈小于 $5^{\circ}$ 的俯角。每两台相机之间至少相 距 $200 \mathrm{~m}$ (图1)。本研究使用Ltl 6210 红外相机, 拍照 


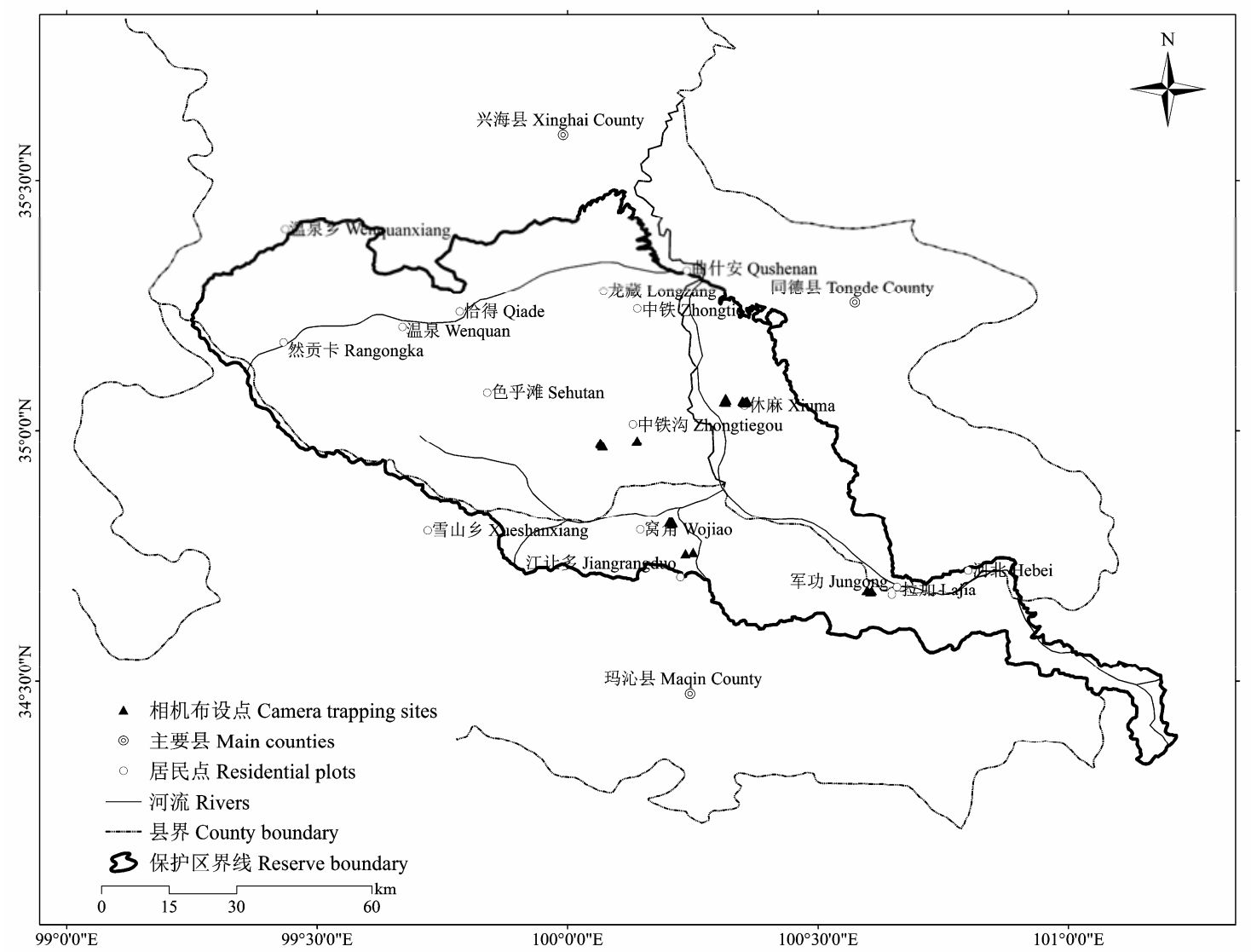

图1 三江源国家级自然保护区中铁一军功分区红外相机安装位点

Fig.1 Camera trapping sites at Zhongtie-Jungong area of Sanjiangyuan National Nature Reserve

像素为 1,200 万，视频尺寸为 $1,080 \mathrm{P}$, 设置为“拍照 + 视频”模式, 连续 2 次拍照最短时间间隔为 $2 \mathrm{~min}$, 采 用 $24 \mathrm{~h}$ 监测。

\section{2 数据分析}

对于获得的相片数据(视频同样被视为照片处 理), 去除未拍到兽类的照片; 在处理连续照片时, 为降低同一物种照片的自相关性, 以30 min为间隔 分开的照片作为 1 次独立捕获 (Yasuda, 2004; Michalski \& Peres, 2007), 即如果同一相机在30 min 中内连续多次拍到同一物种, 只保留拍到数量最多 的一张照片。拍摄率(capture rate, $C R$ )计算公式如下 (Rovero et al, 2014):

$$
C R=(N \times 100) / T
$$

式中, $N$ 为拍摄到的兽类独立照片数, $T$ 为总有效监 测日。

各物种日活动强度指数 $(D I I)$ :

$$
D I I=(N i / N) \times 100
$$

式中, $i$ 为时间段，如6:00-7:59则记为 $6 ; N i$ 为 $i$ 时间拍 摄到某种野生动物的有效照片数; $N$ 为拍摄到对应 野生动物的总个体数量; DII越大, 则表示该动物在 $i$ 时段的活动越强。

为进一步了解野生有蹄类和家畜活动时间的 差异，我们将未拍到家畜的红外相机中野生有蹄类 日活动节律，与拍到家畜的红外相机中野生有蹄类 活动节律进行对比分析, 利用Chi-square检验分析 野生有蹄类和家畜日活动节律差异; 同时，利用 Kruska-Wallis $\mathrm{H}$ 检验比较不同放牧强度(以家畜拍 摄率作为替代指标)下野生兽类拍摄率的差异。数据 分析在SPSS 19.0中进行。

\section{2 结果}

调查过程中丢失 2 台相机, 另有 2 张内存卡无法 读取数据, 故只有 43 个位点的相机正常工作, 其中 37 个位点拍摄到野生兽类, 6 个位点未拍摄到。调查 
累计 2,984相机日, 共拍到 2,486 张兽类照片, 去除 同一物种在同一地点的连续照片, 共获得独立照片 698张。可以明确鉴定出物种的有效照片 660 张, 其 中, 野生兽类330张, 家畜330张; 不能鉴定到种的 小型啮齿类照片有 15 张, 无法鉴定的照片有 23 张。 从物种累积曲线可以看出, 通过 2 个多月的红外相 机监测, 兽类种类数已趋于饱和(图2)。

在中铁一军功分区调查期间，红外相机共拍摄 到13种野生兽类, 隶属4目7科。其中兔形目1种, 啮 齿目 2 种, 食肉目6种, 偶蹄目4种(附录1)。独立照片 位于前5位的野生兽类依次是马鹿(Cervus elaphus) (105张)、藏狐(Vulpes ferrilata) (62张)、喜马拉雅旱 獭(Marmota himalayana)(51张)、高原兔(Lepus oiostolus)(43张)和马鹿(28张)。位点分布前5位的野 生兽类依次是马鹿( 22 个)、藏狐(20个)、马谢 $(15$ 个)、 喜马拉雅旱獭(15个)和高原兔(12个)。在记录到的野 生兽类中, 国家I级重点保护野生动物有马鹿和林 䵇2种; 国家II级重点保护野生动物有金猫(Catopuma temminckii)、石貂(Martes foina)、岩羊(Pseudois nayaur) 和马鹿 4 种; 列入CITES附录I的有金猫 1 种, 列入附录II的有狼(Canis lupus)、豹猫(Prionailurus

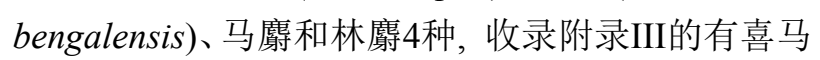
拉雅旱獭1种; 马鹿和林鹿2种被IUCN红色名录列 为濒危物种(EN), 金猫和猪獾(Arctonyx collaris) 2 种被列为近危物种(NT) (IUCN, 2016)。中国特有物 种有狼、藏狐、石貂、马㭩、马鹿、岩羊、喜马拉 雅旱獭和高原兔 8 种。在地理区系构成上, 13 种兽类

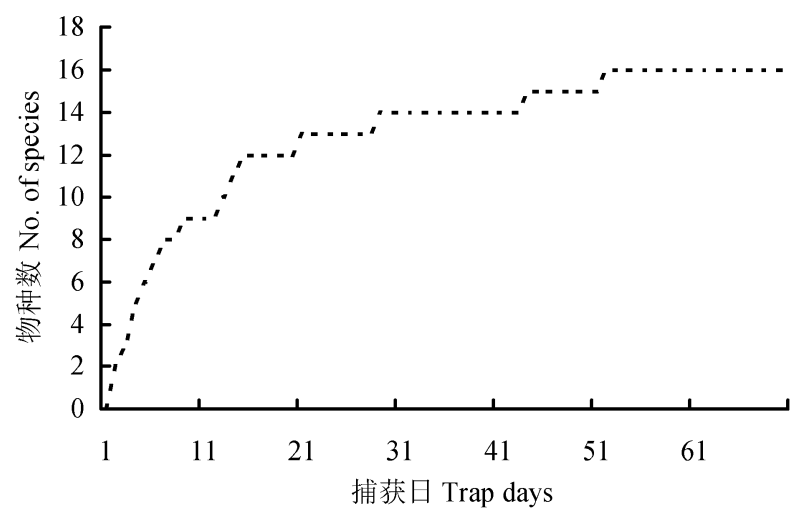

图2 随时间增长监测到兽类数量的增长曲线

Fig. 2 Curves of mammalian species captured by camera traps with increased trap days
中有古北界 8 种, 东洋界 3 种, 广布种 2 种。

野生有蹄类和家畜日活动节律存在显著差异 $\left(\chi^{2}=221.85, d f=11, P=0.000\right)$ 。野生有蹄类日活动 呈现 2 个高峰期, 分别出现在 06:00-08:00 和 20:00-22:00; 家畜日活动只有 1 个高峰期, 活动时 间较长, 集中在10:00-16:00, 然后活动强度逐渐下 降(图3)。

由于其他野生有蹄类被红外相机拍摄的独立 照片数量较少, 我们只分析在有无家畜出现的情况 下马鹿日活动节律的差异。结果表明, 有家畜出现

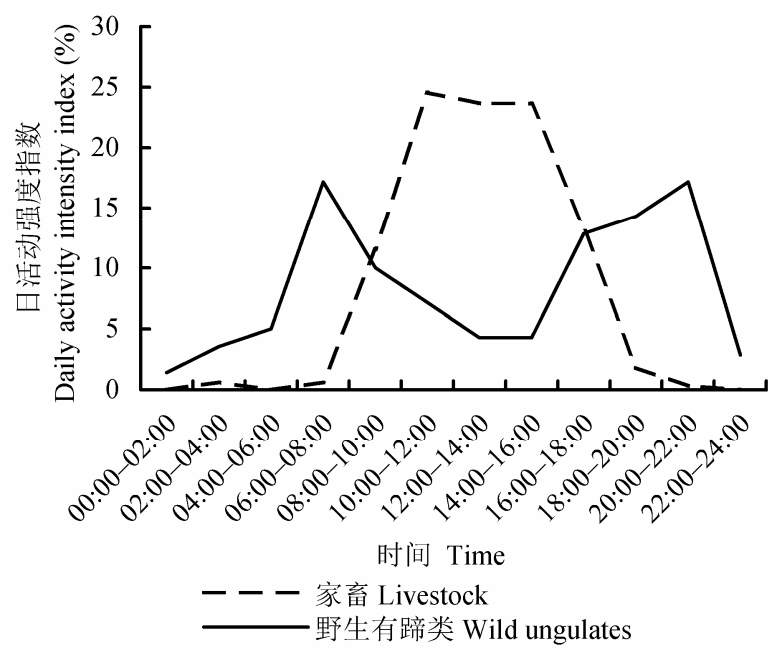

图3 研究区域家畜和野生有蹄类日活动强度指数

Fig. 3 Daily activity intensity index of livestock and wild ungulates in the study area

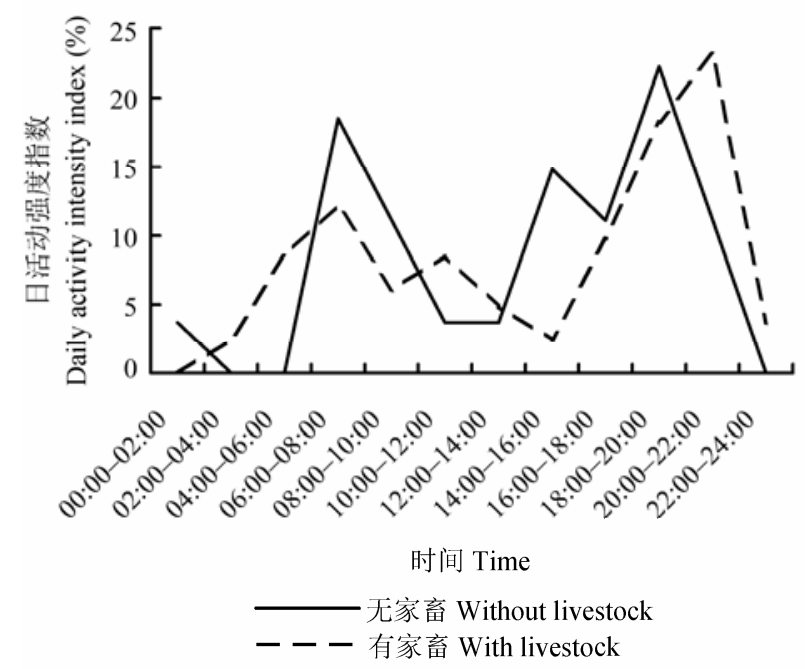

图4 有无家畜出现情况下马鹿日活动强度指数差异

Fig. 4 The daily activity intensity index of red deer when with/without livestock in the same area 
与无家畜出现, 马鹿日活动节律无显著差异 $\left(\chi^{2}=\right.$ $16.29, d f=11, P=0.130)$, 但是在无家畜区域, 在 14:00-16:00马鹿活动出现 1 个小高峰, 而在有家畜 区域, 此时马鹿活动指数为全天最低(图4)。

在不同放牧强度下，野生兽类拍摄率无显著差 异 $\left(\chi^{2}=0.498, d f=2, P=0.780\right)$ 。家畜拍摄率为 0 时 (无家畜出现), 野生兽类拍摄率为 8.76 ; 家畜拍摄 率 $<10$ 时, 野生兽类拍摄率为 10.33 ; 家畜拍摄率 $>$ 10 时, 野生兽类拍摄率为 15.51 (附录2)。

\section{3 讨论}

本研究是中铁一军功分区有关野生兽类多样 性资源的首次报道。相比整个三江源保护区记录到 85 种野生兽类而言(李迪强和李建文, 2002), 本次在 中铁一军功分区拍摄到的野生兽类资源相对较少, 可能有以下 3 个方面的原因: (1)《三江源保护区科学 考察报告》中覆盖了全区 31.8 万 $\mathrm{km}^{2}$ 的区域和更多的 植被类型, 中铁-军功分区只是三江源保护区18个 分区之一; (2)红外相机放置时间较短, 相机数量和 覆盖的区域有限; (3)红外相机主要放置在林地和灌 木丛中, 未能全面记录生活在草地的小型兽类(例 如食虫目和啮齿目动物) 以及生活在高山裸岩的兽 类(如雪豹)。

本研究表明野生有蹄类有 2 个活动高峰期, 分 别出现在6:00-8:00和20:00-22:00, 对比同域分布的 家畜(10:00-16:00) 日活动节律, 发现两类动物的日 活动高峰恰好完全错开, 这种时间生态位分化可能 与野生有蹄类生物学特性和物种间共存机制有关。 一方面, 大多数野生有蹄类本身具有晨昏性活动节 律, 如马鹿 ${ }^{\circledR}$ 、马鹿(王兆锭和张鹏, 1997)、岩羊(闵 永峰等, 2006)、林輒(贾晓东等, 2014)等, 活动高峰 都出现在日出和日落前后; 另一方面, 同域共存的 家畜和野生有蹄类在栖息生境和食性上重叠，时间 生态位分化可能是这两类物种共存的基础。在无家 畜分布区, 马鹿在14:00-16:00出现1个小的活动高 峰, 而在有家畜分布区马鹿在14:00-16:00的活动指 数降为全天最低, 而14:00-16:00正是家畜活动的高 峰期, 因此, 可以推断马鹿为避免与家畜竞争, 调 整了活动节律。放牧不可避免地会给野生有蹄类活

(1) 胡否 (2013) 基于红外自动相机技术的马鹿和狍活动节律与马 鹿集群行为. 硕士学位论文, 北京林业大学, 北京.
动造成影响, 野生有蹄类避开家畜活动高峰期, 也 是其采取降低自身暴露风险的策略之一。尤其值得 注意的是, 在家畜拍摄率高的位点野生兽类的拍摄 率也高, 证明了野生兽类与家畜之间存在激烈的资 源竞争关系, 家畜拍摄率较高 $(>10)$ 的区域是食物 和水源最丰富、隐蔽性最好的区域, 野生兽类也频 繁利用这些区域; 而家畜拍摄率较低 $(<10)$ 的区域, 栖息地质量偏低, 野生兽类也较少利用这些区域。

鉴于中铁-军功分区海拔较高, 氧气极度稀薄, 加之复杂多样的地形及道路可通达性, 利用红外相 机进行野生兽类资源调查和长期监测是最有效的 手段。但由于调查时间较短, 加之调查区域有限, 无法精确掌握保护区野生兽类资源多样性现状及 其分布, 还需在更大区域内展开长期调查和监测。 同时, 还需要调查放牧、围栏等干扰对野生兽类造 成的影响, 为兽类资源多样性保护和管理提供数据 支持。

致谢: 感谢三江源国家级自然保护区全体工作人员 对本研究给予的大力支持。

\section{参考文献}

International Union for Conservation of Nature (IUCN) (2015) The IUCN Red List of Threatened Species, Version 2015-4. $\mathrm{http}: / /$ www.iucnredlist.org. (accessed on 2016-01-25)

Jia XD, Liu XH, Yang XZ, Wu PF, Songer M, Cai Q, He XB, Zhu Y (2014) Seasonal activity patterns of ungulates in Qinling Mountains based on camera-trap data. Biodiversity Science, 22, 737-745. (in Chinese with English abstract) [贾 晓东, 刘雪华, 杨兴中, 武鹏峰, Songer M, 蔡琼, 何祥 博, 朱云 (2014) 利用红外相机技术分析秦岭有蹄类动 物活动节律的季节性差异. 生物多样性, 22, 737-745.]

Li DQ, Li JW (2002) Biodiversity in the Sanjiangyuan Reserve-Sanjiangyuan Nature Reserve Scientific Survey Report. China Science and Technology Press, Beijing. (in Chinese) [李迪强, 李建文 (2002) 三江源生物多样性一三 江源自然保护区科学考察报告. 中国科学技术出版社, 北京.]

Michalski F, Peres CA (2007) Disturbance-mediated mammal persistence and abundance-area relationships in Amazonian forest fragments. Conservation Biology, 21, 1626-1640.

Rovero F, Martin E, Rosa M, Ahumada J, Spitale D (2014) Estimating species richness and modeling habitat preferences of tropical forest mammals from camera trap data. PLoS ONE, doi: 10.1371/journal.pone.0103300.

Wang ZD, Zhang P (1997) Living habits and protective measures of musk deer at Helan Mountain. Inner Mongolia For- 
estry Survey Design, (1), 19-22. (in Chinese with English abstract) [王兆锭, 张鹏 (1997) 贺兰山林区马㭩的生活 习性及保护措施. 内蒙古林业调查设计, (1), 19-22.]

Yan YF, Wang LC, Zhu J, Ni ZY, Luo TW, Liu NF (2006) Preliminary study on ecological behavior of blue sheep in Dongdashan Nature Reserve, China. Chinese Journal of Zoology, 41(4), 53-59. (in Chinese with English abstract) [间
永峰，王留臣，朱杰，倪自银，雒天伟，刘迺发 (2006) 甘肃东大山自然保护区岩羊生态行为的初步观察. 动物 学杂志, 41(4), 53-59.]

Yasuda M (2004) Monitoring diversity and abundance of mammals with camera traps: a case study on Mount Tsukuba, central Japan. Mammal Study, 29, 37-46.

(责任编委：蒋学龙 责任编辑：问文杰)

\section{附录 Supplementary Material}

附录12015年6-9月三江源自然保护区中铁一军功分区红外相机拍摄的兽类名录

Appendix 1 Mammalian species captured by infrared camera in Sanjiangyuan National Nature Reserve from June to September, 2015.

http://www.biodiversity-science.net/fileup/PDF/2016053-1.pdf

\section{附录2 不同放牧强度下野生兽类拍摄率}

Appendix 2 The capture rates of wild mammalian under different grazing intensities http://www.biodiversity-science.net/fileup/PDF/2016053-2.pdf 


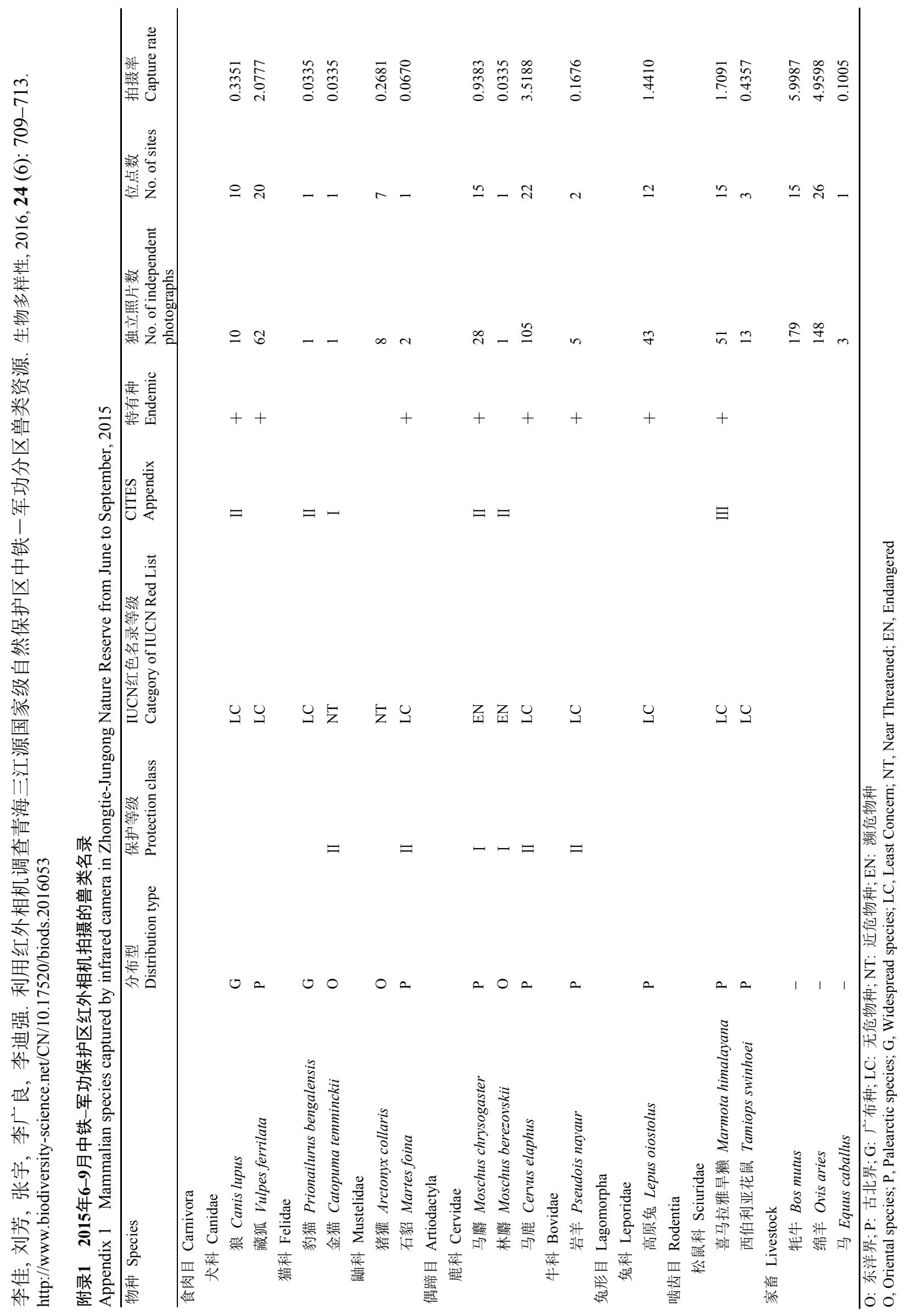




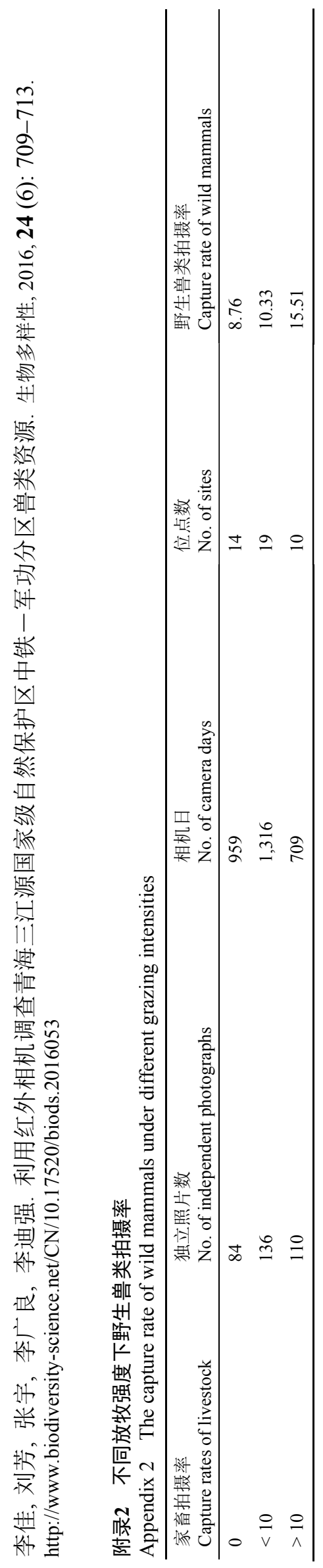

